\title{
Design and Analysis of Roller for Hot Rolling Mill
}

\author{
Mayur Kadu', Prof. S. M. Awatade ${ }^{2}$ \\ ${ }^{1} P G$ Student, ${ }^{2}$ Assistant Professor \\ Mechanical Engineering Department, Priyadarshini College of Engineering, Nagpur - India.
}

Received on: 20 June, 2021

Revised on: 23 July, 2021

Published on: 25 July, 2021

\begin{abstract}
There are three zones in rolling process. These are Backward or lagging zone, Neutral Zone, Forward or leading zone. Deformation is the change in dimensions or form under the action of applied forces. Manufacturing line core mills in steel production for hot strip rolling shape steel and provide its characteristic sheet properties. A tandem mill is one of these configurations which restricts the strip thickness and removes the surface layer or scale, Hot metal is travelling a long distance between roughing mill and a Steckel finishing mill during hot rolling process in a steel plant which resulted in heat loss. Since, the metallurgical qualities of finished product are closely related to the accurate control of temperature of the material during the hot rolling process, the heat in the furnaces maintains the slab temperature at high level at the cost of more fossil fuels. Temperature of the work piece influences spread appreciably. Breakages of work roll journals caused by bending or torque are mainly spontaneous ruptures due to high peak loads. This is also valid for barrel breakage of work rolls and in particular for 4-Hi work rolls. Journals breaking due to high torque on the drive end of work rolls have to be considered as predetermined breaking points in the case of mechanical overloads from setting the wrong roll gap, foreign bodies entering the roll gaped. This applies if there is no other protection equipment against torsion overloads or if this equipment is not working correctly.
\end{abstract}

Keywords- Empirical Methods, Homogeneous Deformation Method, strain and temperature distribution, Slip Line Analysis.

\section{I- INTRODUCTION}

$\mathbf{T}$ oday, there are roll grades available which provide good performance down to discard size without abnormal stock loss for all established rolling operations if standard rolling conditions prevail. Of course, correct handling of the rolls is essential including campaign length and adequate dressing practice with appropriate non-destructive testing. In addition, measurement of additional features such as wear profile and work hardening can also be Beneficial. When specifying work roll grades for wide strip mills, roll manufacturers need to know the rolling conditions and in particular the Finishing Mill stand number in which the roll will be used, the specific rolling loads per unit of strip Width and the maximum rebinding applied through the journals. These facts will determine the selection of materials for the core and working layer on the barrel surface for compound rolls. Despite careful attention from the roll supplier and user, roll failures will happen in service which lead to partial or total loss of the rolls and may even cause subsequent damage to rolling equipment. These frustrating failures can have different kinds of origin related to either roll manufacture or the specific rolling conditions residual stress. These two factors are very harmful for fatigue behavior of materials. Generally material removal process such as machining, grinding, etc. lead poor surface finish. After that, the material goes under super finishing process. Nowadays burnishing process becomes more popular as a finishing process.

\section{II- DESIGN}

In predicting loads for metal forming modelling, the main purpose is to predict exactly how and where the material will flow. The traditional empirical analysis models are 


\section{International Journal of Innovations in Engineering and Science, www.ijies.net}

based on flat rolling theory and cannot meet the modem requirements of high precision, high quality and high efficiency. Till now, the exact solutions for hot rolling load have not been found, however, a number of different methods have been developed. Two methods are used for approximate evaluation of forces. The first is called the lower-bound analysis while the second is called the upper-bound analysis. These are underestimate or overestimate of the actual forming load. The real load will lie between these lower and upper bounds. The lower bound analysis predicts loads that are less than or equal to the exact load needed to produce full plastic deformation. The method can take into account frictional forces and always gives a lower bound (underestimate) of the actual forming load. It is particularly useful in assessing the affects of friction on a given forming process. For most design or operational purposes it is more important to know the upper bound solution since this will ensure that the calculated load is sufficient to complete the forming operation.

Table-1 The following data are based on the EUR report

\begin{tabular}{|l|l|}
\hline Radius of the rollers & $\mathrm{R}=300 \mathrm{~mm}$ \\
\hline Slab Length & $\mathrm{L}=300 \mathrm{~mm}$ \\
\hline Slab Width & $\mathrm{W}=350 \mathrm{~mm}$ \\
\hline Slab Thickness & $\mathrm{H}=100 \mathrm{~mm}$ \\
\hline Thickness reduction & $13.2 \%$ \\
\hline Friction coefficient & $\mu=0.35$ \\
\hline Young modulus & $\mathrm{E}=100 * 10^{3} \mathrm{MPa}$ \\
\hline Poisson coefficien & $\mathrm{V}=0.35$ \\
\hline Yield stress & $\sigma_{\mathrm{y}}=33.3 \mathrm{MPa}$ \\
\hline
\end{tabular}

\subsection{Calculating force:}

According to Sims (1954). Rolling separation force $\mathrm{P}=$ $\mathrm{WI}_{\mathrm{d}} \mathrm{Q}_{\mathrm{p}} \mathrm{S}_{\mathrm{p}}$

1. Mean work piece width $\mathrm{W}$

Where $\mathrm{W}=350 \mathrm{~mm}=350 / 25.4=13.78 \mathrm{in}$

2. Projected arc of contact $I_{d}$ $\mathrm{I}_{\mathrm{d}}=\mathrm{L}_{\mathrm{d}}=\sqrt{R \Delta h}=\sqrt{300 *(100-86.8)}=2.48 \mathrm{in}$

3. Geometrical coefficient $\mathrm{Q}_{\mathrm{P}}$

Assumption $\mathrm{R}^{\prime}=\mathrm{R}$ i.e. no flatten

$\mathrm{R} / \mathrm{h} 2 \approx \mathrm{R} / \mathrm{h} 2=300 / 86.8=3.46$.

\section{III- ANALYSIS}

Slip-line field analysis allows the introduction of a more realistic model of metal flow. It utilizes a graphical approach, which presents the flow pattern in the deformed metal in a point by point basis. Alexander (1955) presented the first slip line field solution for hot rolling of wide sheets. He only offered a single and simple geometry of rolling. Crane and Alexander (1966) used new slip line fields for hot rolling to predict the deformation of the metal for a wide range of geometries. Dewhurst et al. (1973) presented a series of slip line field solutions for hot rolling of wide sttip, which was further discussed by Druyanov (1973). Slip line field solutions permit the determination of stress and velocity distributions in the plastic deformation zone. However, this method is only valid for assumed rigidperfectly plastic non-hardening materials (Shabaik 1968).

The basic assumption: is that strain is continuous and the volume of the material remains constant when its shape changes. The shape change must correspond to the flow velocity of the material. The method is more valuable in metalworking, where it is important to know the upper bound solution, to ensure the calculation of the load necessary to complete the forming operation. A detailed description of the technique would be lengthy. However, Figure 1. Illustrates a simple upper bound solution for plane strain extrusion. It has a reduction in area of $2: 1$. Complex shape change will not usually be plane strain and hence the deformation will only be approximated by this calculation. The simple example demonstrates the principles.

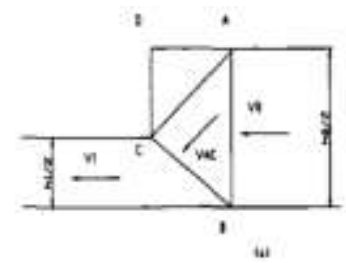

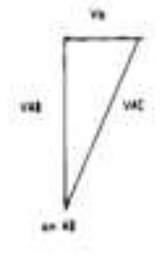
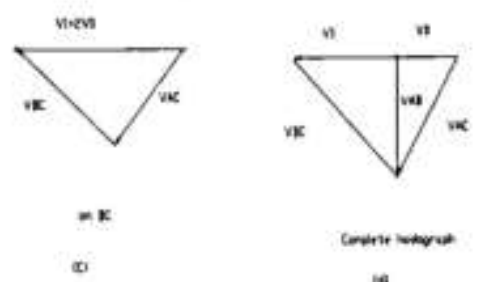

Fig 1- Upper bound solution for strain extrusion (Lyndon 1990)

The analysis of the Rolls and Billet is done in Ansys 15.0 and the analysis reports are as shown below. The geometry and the mesh model in Ansys are as shown in the Fig. 2 below respectively. 


\section{International Journal of Innovations in Engineering and Science, www.ijies.net}

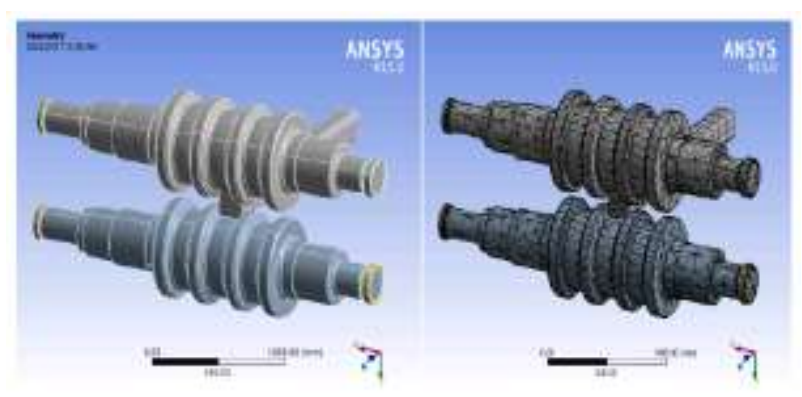

Fig.2 - Geometry of the Rolls and Billet

\section{IV- FUTURE SCOPE}

Hot wear rate is directly proportional to the normal pressure on roll surface. Average rolling pressures can be considered to be in range 100 - $300 \mathrm{MPa}$. The corresponding cyclic stresses, amplified by thermal cycles, in roll surfaces are estimated to amount to \pm 500 MPa.

Cyclic loads result in material fatigue and other forms of surface deterioration. Besides the well-known mechanisms of cyclic softening and corrosion fatigue, there is growing evidence of the damaging influence of tensile stress during the contact fatigue, leading to cracking and pitting. In addition, it has been found that cyclic pre-stressing has a significant influence on the material removal process in sliding wear. A related question is the actual distribution patterns of the rolling loads and stresses. The observed non-uniform wear, particularly the unsymmetrical wear of the symmetrical calibres, illustrates the significance of the irregular pressure distribution. The appreciation of these contrasts in stresses has led to the introduction of different materials for top rolls and bottom rolls in the practice of section rolling. If metal flow is not appropriately allowed for in roll pass design, metal is unnecessarily forced to exert additional localised pressure and wear on the groove walls. There are in fact basic principles for roll pass design in existence, where roll wear is among the main criteria. Higher loads and draft non-uniformity should be applied in the initial passes and they ideally should diminish in the finishing passes. Rolling loads and stress distributions should be designed to ensure stable and uniform wear of finishing calibres. Corrosion fatigue can be suppressed by proper design considerations aimed at reducing stress. The tensile component of stress causes stress corrosion. Residual compressive stresses, deliberately introduced through an adequate heat treatment, will suppress crack initiation and growth, as well as stress corrosion and fatigue. Geometrical aspects (eg roll diameter) have considerable effect on tool life via associated stress and heat concentration.

Considering the feasibility of influencing stresses and loads as process variables that can be controlled by roll pass design, this established correlation between stresses and surface deterioration must be an important aspect of research into roll wear.

\section{V- CONCLUSION}

The combination of both Finite element method and Matrix-based hot roll design provides a hot roll design methodology with a systematic approach. It includes the existing formulae, empirical data, experimental graphics, and technical methods for hot roll pass design. This study has included a lot of existing empirical knowledge of experts as well as the results of research into new approaches.

For specific hot rolled products, by comparing the different formulae conditions of application, graphics data and computer simulation results, the optimum formulae and data can be chosen after discussion between the designers using the matrix. The optimum manufacturability of the rolled product is thus ensured from the optimum design, as early as possible in the design stage.

Further; the matrix also provides a systematic viewpoint and facilitates the consideration of hot roll design, not only based on the traditional methods, but also from the more modern techniques such as: Concurrent Engineering (CE), the planning of manufacturing, Computer-aided Design (CAD), Finite Element Method (FEM) and other methods.

Steel rolling is recognised as one of the most important industrial processes. Rolling using grooved rolls (as a category different from groove-less rolling) is the most common practice in production of steel sections. Key tools in this process are the rolls that contribute up to 15 $\%$ of production costs. A main cause of roll consumption is due to continuous wear, complex process where mechanical and thermal fatigue combines with impact, abrasion, and corrosion. The necessity to compensate for the non-uniform wear during machining is an additional aspect of roll consumption. An area of specific interest is concerned with abrasive wear within the environment of rolling in grooves, where the nature of the deformation zone can accelerate roll surface deterioration.

The published research into roll wear is mainly concerned with the effects of roll material, oxide scales, temperature, normal force and sliding velocity. Though a selective 
Vol. 6, No. 8, 2021, PP. 53- 56

\section{International Journal of Innovations in Engineering and Science, www.ijies.net}

application of numerous roll materials is decisive for roll consumption, there is no general index for determining their resistance to wear. Several authors have examined how temperature has affected the wear of various roll materials via corrosion, formation of oxide films and fatigue. Detrimental influences of the rolling load and relative slip on hot wear are clearly proven. On the other hand, the published works give very little, if any, information on the possible ranking and interactions of wear factors. In addition, there is a lack of knowledge about the influence of bulk stress in roll material on abrasion..

\section{REFERENCES}

[1] Arnell, R.D., Davies, P.B., Halling, J. and Whomes, T.L. (1993) Tribology, Principles and Design Applications, The Macmillan Press Ltd., Springer - Verlag, NY, pp.54-71.

[2] Chausevich, M. (1983) Rolling of Metallic Materials, VeselinMaslesa, Sarajevo, Vol. 30, No. 2.Corbett, R.B. (1990) Rolls for the Metalworking Industries, Iron and Steel Society, Warrendale,PA, Vol. 273.

[3] .Erdem, G. and Taptik, Y. (2005) 'Effect of hot rolling conditions to produce deep drawing quality steels for continuous annealing process', Journal of Materials Processing Technology,Elsevier, Vol. 170, Nos. 1-2, pp.17-23.

[4] Gahr, K-H.Z. (1987) Microstructure and Wear of Materials, Elsevier, Amsterdam Netherlands, Vol. 90, pp.253-261.

[5] Ginzburg, V.B. (1989) Steel Rolling Technology, Theory and Practice, Marcel Dekker, New York, NY, Vol. 505.

[6] Jahanmir, S. (1981) 'Fundamentals of tribology', in N.P. Suh (Ed.): Proc. Int. Conf., MIT Press,London, UK, Vol. 455 . 